\title{
Cardiovascular and Thromboembolic Diseases in Oncology: Novel Aspects and Revisited Issues
}

\author{
Antonella Tufano, MD, $\mathrm{PhD}^{1}$ Antonio Coppola, $\mathrm{MD}^{2}$ \\ ${ }^{1}$ Department of Clinical Medicine and Surgery, Federico II University \\ Hospital, Naples, Italy \\ 2 Regional Reference Center for Inherited Bleeding Disorders, \\ Department of General and Specialist Medicine, University Hospital \\ of Parma, Parma, Italy \\ 3 Department of Haematology and Transfusion Medicine, Carlo Poma \\ Hospital, Mantova, Italy
}

Semin Thromb Hemost 2021;47:895.

This issue of Seminars in Thrombosis and Hemostasis (STH) is dedicated to the memory of Maurizio Galderisi, who began the journey of developing this issue of the journal as a CoGuest Editor, but suddenly passed away during its development. The deadly pandemic took him away from his loved

\author{
Massimo Franchini, MD ${ }^{3}$
}

Address for correspondence Antonio Coppola, MD, Regional Reference Center for Inherited Bleeding Disorders, Department of General and Specialist Medicine, University Hospital of Parma, Via Gramsci, 14, 43126 Parma, Italy (e-mail: ancoppola@ao.pr.it).

ones and many friends, colleagues, and students who all now feel an enormous sense of emptiness, but will also continue to be inspired by the invaluable human and cultural heritage he left as his legacy.
Issue Theme Cardiovascular and Thromboembolic Diseases in Oncology: Novel Aspects and Revisited Issues: Antonella Tufano, MD, PhD, Antonio Coppola, MD, Maurizio Galderisi, MD, and Massimo Franchini, MD (c) 2021. Thieme. All rights reserved. Thieme Medical Publishers, Inc., 333 Seventh Avenue, 18th Floor, New York, NY 10001, USA
DOI https://doi.org/ 10.1055/s-0041-1736476. ISSN 0094-6176. 